\title{
Pemanfaatan Neural Network Perceptron Pada Pengenalan Pola Karakter
}

\author{
Kukuh Yudhistiro \\ kukuh.yudhistiro@unmer.ac.id
}

Fakultas Teknologi Informasi Universitas Merdeka Malang

\begin{abstract}
Various methods on artificial neural network has been applied to identify patterns of characters one using Perceptron algorithm. Perceptron algorithm can be used to identify patterns of characters with various input patterns that resemble letters of the alphabet so perceptron can be trained to recognize it. Perceptron algorithm is an algorithm in a neural network that includes supervised neural network.

Intisari- Berbagai metode pada jaringan syaraf tiruan telah diterapkan dengan menggunakan algoritma Perceptron. Algorit ma Perceptron dapat digunakan untuk mengidentifikasi pola karakter yang dapat dilatih perceptron untuk mengenalinya. Algoritma perceptron adalah algoritma dalam jaringan syaraf tiruan yang mencakup jaringan syaraf tiruan.
\end{abstract}

Kata Kunci- neural network, perceptron, pengenalan pola, algoritma perceptron, deteksi fitur

\section{PENDAHULUAN}

Character recognition merupakan bidang yang termasuk dalam penelitian berbasis jaringan syaraf tiruan. Pada algoritma perceptron vektor pola yang diinputkan adalah vektor pola karakter A, B dan C yang bervariasi. Dari pola yang sudah diberikan, maka langkah selanjutnya adalah melatih jaringan tersebut agar memperoleh bobot $(w)$ dan bias (b) yang diinginkan sehingga dapat membandingkan keluaran jaringan yang didapat dengan target yang sudah ditentukan. Hasil percobaan penulis didapatkan bahwa pengenalan pola A, $\mathrm{B}, \mathrm{C}$ dapat dikenali cukup dalam 3 epoch dengan nilai bobot dan nilai bias tertentu [1][4].

\section{KAJIAN PUSTAKA}

\section{A. Algoritma Perceptron}

Model jaringan perceptron ditemukan oleh Rosenblatt (1962) dan Minsky - Papert (1969). Model tersebut merupakan model yang memiliki aplikasi dan pelatihan yang paling baik pada era tersebut [2].

Arsitektur jaringan perseptron mirip dengan arsitektur jaringan Hebb disajikan pada gambar 1.

Jaringan terdiri dari beberapa unit masukan dan memiliki sebuah unit keluaran. Hanya saja fungsi aktivasi bukan merupakan fungsi biner (atau bipolar), tetapi memiliki kemungkinan nilai $-1,0$ atau 1.

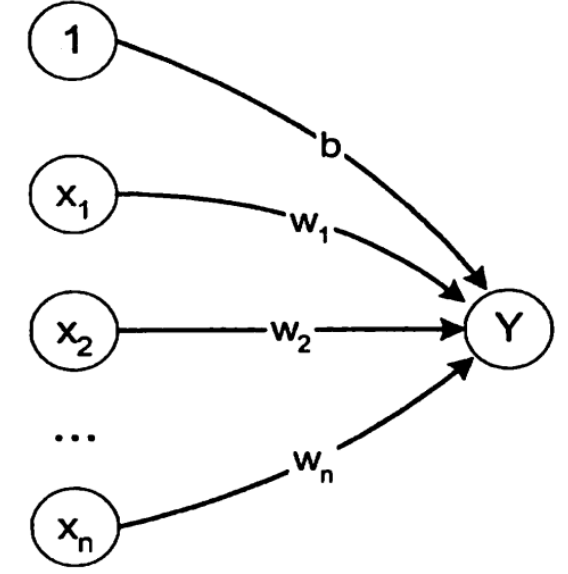

Gambar 1. Diagram jaringan perceptron

Untuk suatu harga threshold $\theta$ yang ditentukan:

$f($ net $)= \begin{cases}1 & \text { jika net }>\theta \\ 0 & \text { jika }-\theta \leq n e t \leq \theta \\ -1 & \text { jika net }<-\theta\end{cases}$

Secara geo metris, fungsi aktivasi membentuk 2 garis sekaligus masing-masing dengan persamaan:

$$
\begin{aligned}
& w_{1} x_{1}+w_{2} x_{2}+\ldots+w_{n} x_{n}+b=\theta \text { dan } \\
& w_{1} x_{1}+w_{2} x_{2}+\ldots+w_{n} x_{n}+b=-\theta
\end{aligned}
$$

\section{B. Training Pada Algoritma Perceptron}

Misalkan:

$$
\begin{array}{ll}
s & \text { adalah vektor inputan } \\
t & \text { adalah target output } \\
\alpha & \text { adalah learning rate (laju pemahaman yang telah } \\
\text { ditentukan) } & \\
\theta & \text { adalah threshold yang ditentukan }
\end{array}
$$

maka algoritma pelatihan perceptron adalah:

1. inisialisasi semua bobot dan bias $(=\alpha)$. Biasanya learning rate diberi nilai $=1$

2. selama ada elemen vektor masukan yang respon unit keluaran tidak sama dengan target, lakukan:
a. set aktivasi unit masukan:$$
x_{i}=s_{i}(i=1, \ldots, n)
$$
b. hitung respon unit keluaran:
net $=\sum_{i} x_{i} w_{i}+b$ 


$$
\mathrm{y}=\mathrm{f}(\text { net })= \begin{cases}1 & \text { jika } \text { net }>\theta \\ 0 & \text { jika }-\theta \leq \text { net } \leq \theta \\ -1 & \text { jika net }<-\theta\end{cases}
$$

c. Revisi bobot pola yang mengandung error $(y<>t)$ dengan persamaan:

$$
\begin{aligned}
& \mathrm{w}_{\mathrm{i}}(\text { baru })=\mathrm{w}_{\mathrm{i}}(\text { lama })+\Delta \mathrm{w} \quad(\mathrm{i}=1, \ldots, \mathrm{n}) \text { dengan } \Delta \mathrm{w}=\alpha \mathrm{t} \mathrm{x}_{\mathrm{i}} \\
& \mathrm{b}(\mathrm{baru})=\mathrm{b}(\text { lama })+\Delta \mathrm{b} \text { dengan } \Delta \mathrm{b}=\alpha \mathrm{t}
\end{aligned}
$$

\section{Proses Pelatihan}

1. Iterasi dilakukan terus sampai semua pola memiliki keluaran jaringan yang sama dengan targetnya (jaringan sudah memahami pola). Iterasi tidak berhenti setelah semua pola dimasukkan.

2. Perubahan bobot hanya dilakukan pada pola yang mengandung kesalahaan. Perubahan tersebut merupakan hasil kali unit masukan dengan target dan learning rate. Perubahan bobot hanya akan terjadi kalau unit masukan $<>$ 0.

3. Kecepatan iterasi ditentukan oleh learning rate $(0 \leq \alpha \leq 1)$ yang dipakai. Semakin besar harga learning rate semakin sedikit iterasi yang diperlukan. Akan tetapi jika learning rate terlalu besar maka akan merusak pola yang sudah benar sehingga laju pemahaman menjadi lambat.

Algoritma pelatihan perceptron lebih baik dibandingkan model Hebb [1][3] karena:

1. setiap kali sebuah pola dimasukkan, hasil keluaran jaringan dibandingkan dengan target yang sesungguhnya. Jika terdapat perbedaan, maka bobot akan dimodifikasi. Jadi tidak semua bobot selalu dimodifikasi dalam setiap iterasinya.

2. Modifikasi bobot tidak hanya ditentukan oleh perkalian antara target dengan masukan, tetapi juga melibatkan suatu laju pemahaman (learning rate) yang nilainya dapat diatur.

3. Pelatihan dilakukan berulang-ulang untuk semua kemungkinan pola yang ada hingga jaringan dapat mengerti polanya. Satu siklus pelatihan yang melibatkan semua pola disebut epoch.

\section{METODE PENELITIAN}

Algoritma untuk mengenali apakah pola inputan yang diberikan menyerupai sebuah karakter A, B atau Catau tidak adalah:

1. Nyatakan tiap pola inputan sebagai matrik bipolar yang elemennya adalah tiap titik dalam pola tersebut

2. berikan nilai target $=+1$ jika pola inputan menyerupai hurug yang diinginkan. Jika sebaliknya, berikan nilai target $=-1$

3. Berikan inisialisasi bobot, bias, laju pe mahaman (learning rate) dan threshold.

4. Lakukan proses pelatihan.

\section{HASIL DAN PEMBAHASAN}

Untuk menentukan vektor masukan, tiap titik dalam pola diambil sebagai ko mponen vektor. Jadi setiap vektor masukan memiliki 9x7 = 63 komponen. Titik dalam pola yang bertanda "\#” diberi nilai $=+1$ dan yang bertanda "." Diberi nilai $=-1$.
Pembacaan pola dilakukan dari kiri ke kanan, dimulai dari baris paling atas.

Berikut adalah pola-pola inputan yang diberikan:

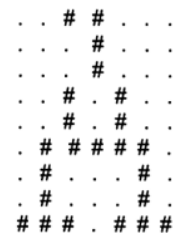

Pola 1

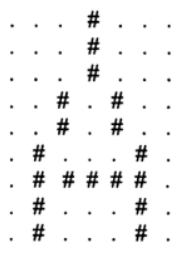

Pola 4

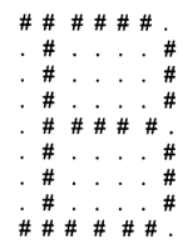

Pola 2

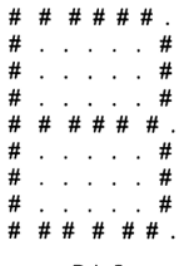

Pola 5

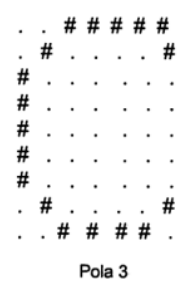

Pola 3

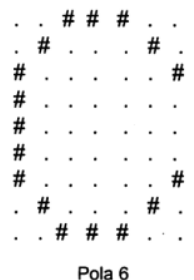

Pola 6
Gambar 2. Pola yang akan diuji

Vektor masukkan pola 1:

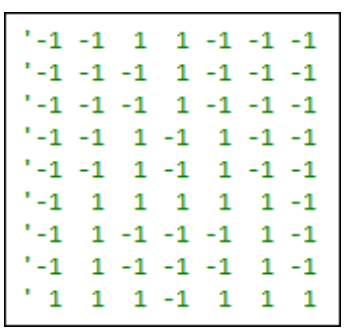

Gambar 3. Pola ke-1

Vektor masukkan pola 2:

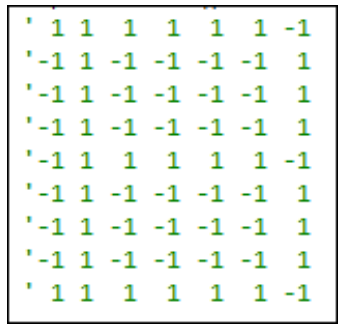

Gambar 4. Pola ke-2

Vektor masukan pola 3:

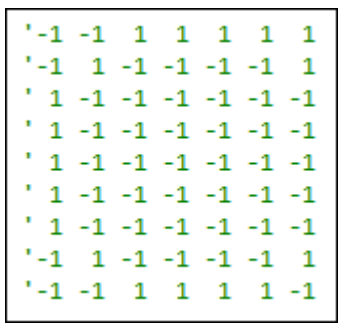

Gambar 5. Pola ke-3 
Vektor masukan pola 4:

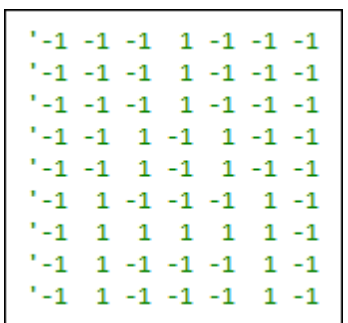

Gambar 6. Pola ke-4

Vektor masukan pola 5:

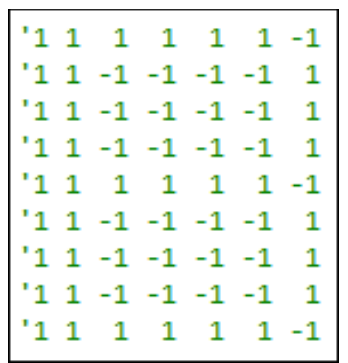

Gambar 7. Pola ke-5

Vektor masukan pola 6:

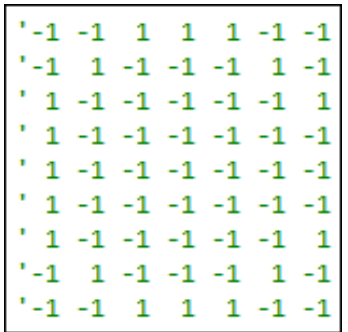

Gambar 8. Pola ke-6

\begin{tabular}{cc}
\hline Pola Masukan & Target \\
\hline Pola 1 & 1 \\
Pola 2 & -1 \\
Pola 3 & -1 \\
Pola 4 & 1 \\
Pola 5 & -1 \\
Pola 6 & -1 \\
\hline
\end{tabular}

Gambar 9. Pola Masukan

Target yang bernilai $=+1$ bila pola masukan menyerupai huruf A. Jika tidak maka target bernilai $=-1$. Pola yang menyerupai huruf A adalah pola 1 dan pola 4 .

Maka perceptron yang digunakan untuk mengenali pola huruf huruf A atau yang lain memiliki 63 buah masukan, sebuah bias dan sebuah unit output.

Misalkan bobot awal $=0$ untuk semua bobot maupun bias, learning rate $\alpha=1$ dan threshold $=0.5$. Pelatihan dilakukan dengan cara memasukkan 63 unit masukan.

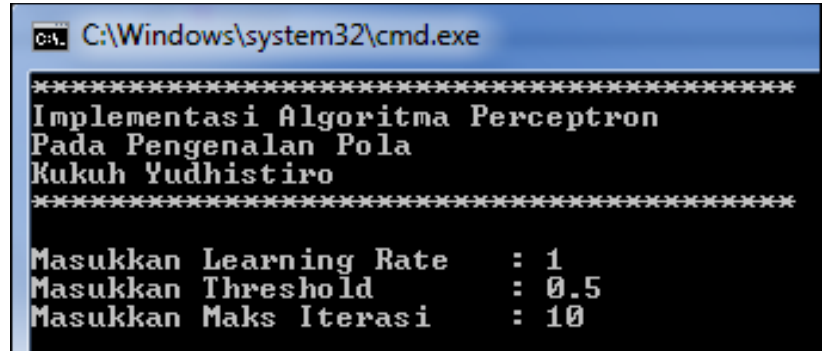

Gambar 10. Input pada program

Dihitung:

$$
\text { Net }=\text { net }=\sum_{i} x_{i} w_{i}+b
$$

Berikutnya, fungsi aktivasi dihitung menggunakan persamaan:

$$
\mathrm{y}=\mathrm{f}(\text { net })= \begin{cases}1 & \text { jika } \text { net }>0.5 \\ 0 & \text { jika }-0.5 \leq \text { net } \leq 0.5 \\ -1 & \text { jika } \text { net }<-0.5\end{cases}
$$

Apabila $\mathrm{f}($ net) $<>$ target, maka bobot dan bias diubah. Proses pelatihan dilakukan terus hingga semua keluaran jaringan sama dengan targetnya.

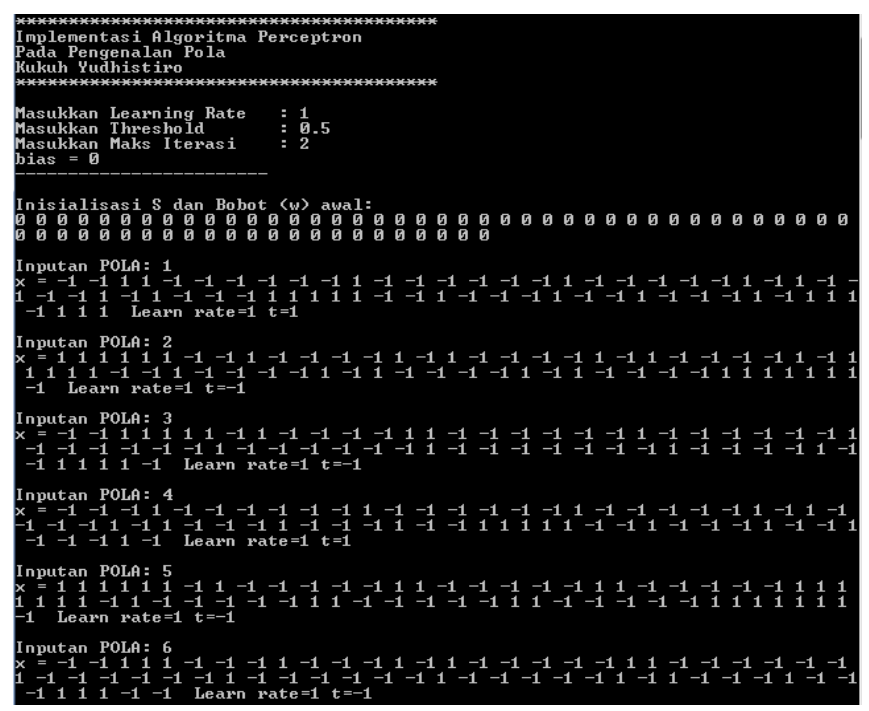

Gambar 11. Pemberian nilai pada vektor setiap pola

Pada baris Inputan Pola, menampilkan x (inputan) yang ditulis pada coding. Jika pada materi tertu lis: 11111 ( 11 x2 1 t). Pada training yang ke 0 atau epoch pertama didapat hasil berikut seperti pada gambar 12:

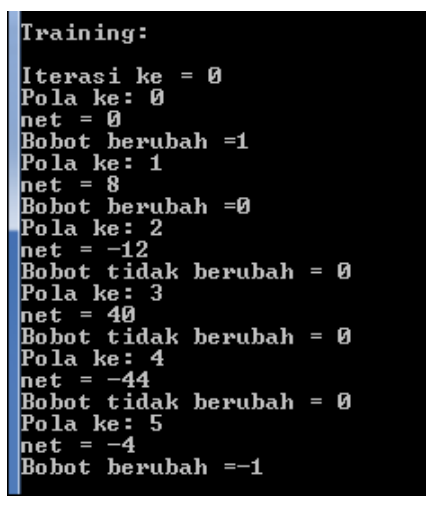


Gambar 12. Epoch ke 1 (iterasi ke 0)

Selama $f(n e t)<>t$ atau $y<>t$, iterasi dilanjutkan. User dapat melakukan perubahan parameter:

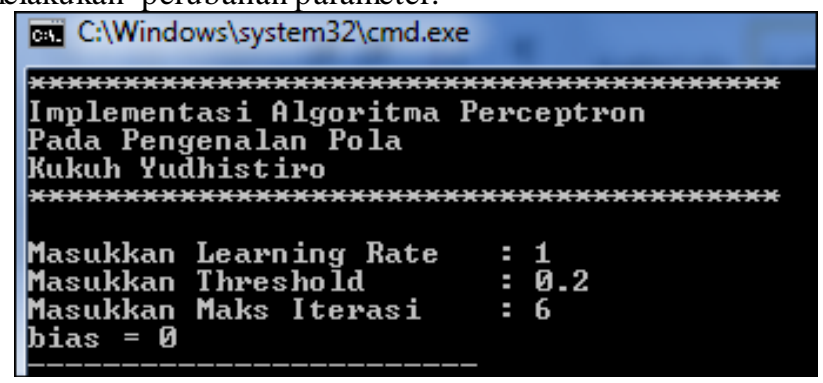

Gambar 13. Pemberian nilai kembali untuk uji ulang

\begin{tabular}{|c|c|c|c|c|c|c|c|c|c|c|c|}
\hline & $\begin{array}{l}\text { isuk } \\
x_{2}\end{array}$ & & $\begin{array}{c}\text { Target } \\
t\end{array}$ & net & $\begin{array}{c}y \\
=f(\text { net })\end{array}$ & $\begin{array}{l}\text { Perubb } \\
\left(\Delta w_{1}\right.\end{array}$ & ahan $\mathrm{E}$ & $\begin{array}{l}\text { Bobot } \\
\Delta b)\end{array}$ & $\begin{array}{l}\text { Bobr } \\
\left(w_{1}\right.\end{array}$ & $\begin{array}{l}\mathrm{w}_{2} \\
\mathrm{w}_{2}\end{array}$ & \\
\hline \multicolumn{9}{|c|}{ inisialisasi } & (0 & 0 & 0) \\
\hline (1 & 1 & 1) & 1 & 0 & 0 & (1 & 1 & 1) & (1 & 1 & 1) \\
\hline$(1$ & 0 & 1) & -1 & 2 & 1 & $(-1)$ & 0 & $-1)$ & (0 & 1 & 0) \\
\hline (0 & 1 & 1) & -1 & 1 & 1 & (0 & -1 & $-1)$ & $(0$ & 0 & $-1)$ \\
\hline (0) & 0 & 1) & -1 & -1 & -1 & (0 & 0 & 0) & (0) & 0 & $-1)$ \\
\hline
\end{tabular}

Gambar 14. Perhitungan secara tabel

\begin{tabular}{||l||l||} 
Iterasi ke $=0$ \\
Pola ke: $\theta$ \\
net $=0$ \\
Bobot berubah $=1$ \\
Pola ke: 1 \\
net $=1$ \\
Bobot berubah $=0$ \\
Pola ke: 2 \\
net $=2$ \\
Bobot berubah $=-1$ \\
Pola ke: 3 \\
net $=-3$ \\
Bobot tidak berubah $=-1$
\end{tabular}$\quad \mid \begin{aligned} & \text { Iterasi ke }=1 \\
& \text { Oola ke: } \theta \\
& \text { net }=1 \\
& \text { Bobot berubah }=0 \\
& \text { Pola ke: } 1 \\
& \text { net }=0 \\
& \text { Bobot berubah }=-1 \\
& \text { Pola ke: } 2 \\
& \text { net }=1 \\
& \text { Bobot berubah }=-2 \\
& \text { Pola ke: } 3 \\
& \text { net }=-6 \\
& \text { Bobot tidak berubah }=-2\end{aligned}$

Gambar 15. Epoch 1 dan 2

\begin{tabular}{||l|l|}
\hline Iterasi ke $=2$ & Iterasi ke $=3$ \\
Pola ke: 0 & Pola ke: 0 \\
net $=2$ & net $=3$ \\
Bobot berubah $=-1$ & Bobot tidak berubah $=-3$ \\
Pola ke: 1 & Pola ke: 1 \\
net $=-1$ & net -3 \\
Bobot berubah $=-2$ & Pobot tidak berubah $=-3$ \\
Pola ke: 2 & nola ke: 2 \\
net $=0$ & nobot tidak berubah $=-3$ \\
Bobot berubah $=-3$ & Pola ke: 3 \\
Pola ke: 3 & net $=-9$ \\
net = -9 & Bobot tidak berubah $=-3$ \\
Bobot tidak berubah $=-3$
\end{tabular}

Gambar 16. Epoch 3 dan 4

\begin{tabular}{|l|} 
Iterasi ke $=9$ \\
Pola ke: 0 \\
net $=3$ \\
Bobot tidak berubah $=-3$ \\
Pola ke: 1 \\
net $=-3$ \\
Bobot tidak berubah $=-3$ \\
Pola ke: 2 \\
net $=-3$ \\
Bobot tidak berubah $=-3$ \\
Pola ke: 3 \\
net $=-9$ \\
Bobot tidak berubah $=-3$ \\
selesai
\end{tabular}

\section{Gambar 17. Epoch 10}

Dari gambar $17 \mathrm{di}$ atas, bobot tidak berubah lagi sejak epoch 4 (iterasi 3) sampai epoch 10 (iterasi 9)

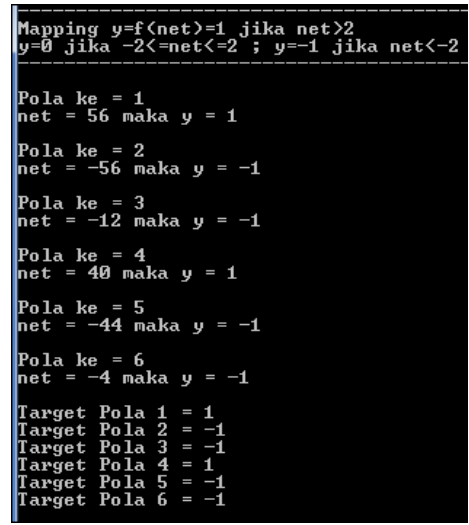

Gambar 18. Hasil perhitungan net dibandingkan dengan Target pola

Dari gambar di atas menunjukkan target pola yang diharapkan sama dengan target awal:

\begin{tabular}{|cc|}
\hline Pola Masukan & Target \\
\hline Pola 1 & 1 \\
Pola 2 & -1 \\
Pola 3 & -1 \\
Pola 4 & 1 \\
Pola 5 & -1 \\
Pola 6 & -1 \\
\hline
\end{tabular}

Gambar 19. Hasil perhitungan net dibandingkan dengan Target pola

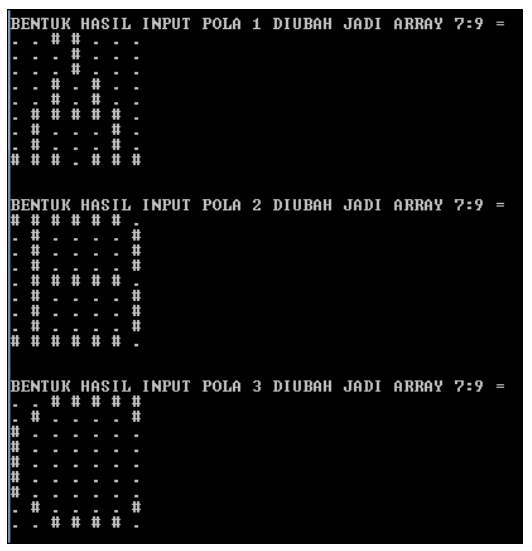

Gambar 20. Tampil hasil pengenalan karakter pola 1,2 dan 3

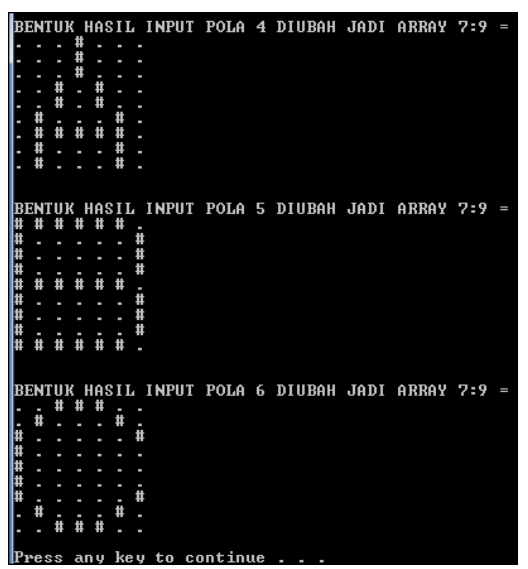

Gambar 21. Tampil hasil pengenalan karakter pola 4,5 dan 6 


\section{KESIMPULAN DAN SARAN}

Dari hasil percobaan pengenalan pola karakter menggunakan algoritma perceptron di atas diperoleh bahwa dengan leaming rate $=1$, bias awal $=0$, threshold $=0.2$ dapat mengenali pola huruf A dengan 3 epoch dimana target pola (y / f(net)) sama dengan target yang diinginkan (t). Algoritma perceptron tersebut juga dapat digunakan untuk pengenalan pola karakter lain.

\section{DAFTAR PUSTAKA}

[1] Siang, Jong Jek. Jaringan Saraf Tiruan dan Pemrogramannya Menggunakan Matlab. Yogyakarta: 2005

[2] Haykin, S., Neural Networks, a Comprehensive Foundation, Prentice Hall, 1994

[3] Demuth, H., Beale, M., Neural Network Toolbox, For Use with MATLAB, The MathWorks, 2001

[4] Stephens, Rod., Visual Basic 2005 Programmer's Reference, Wiley Publishing, Indianapolis: 2005 
